\title{
Proceso constitucional actual en Bolivia: "Aquí comienza un nuevo Estado" (Evo Morales)
}

\author{
Marianna Abramova \\ Universidad Financiera Gubernamental de Rusia
}

En febrero de 2011 cumplen dos años de nueva Constitución vigente de Bolivia lo que nos permite hacer algunas conclusiones. En el referendo de 2009 de los 4 millones de votadores 61,67\% dieron su voto por ella. Los observadores nacionales y extranjeros que vigilaban por la votación, entre ellos estaban los representantes de la Comisión Central Electoral de Rusia, reconocieron que las elecciones habían pasado de una manera organizada, tranquila y sin contravenciones. Este referendo fue no sólo el resultado de aplicar un instrumento corriente de la democracia sino resultó una etapa especial en la construcción constitucional en el país: la Ley Orgánica aprobada en el referéndum ha definido el carácter del desarrollo económico y social del país para próximas décadas, ha consolidado la configuración de nuevo sistema político, ha introducido cambios en el sistema jurídico boliviano en el cual desde este momento va a usar el derecho común indígena en pie de igualdad con otras fuentes de derecho ya existentes.

Bolivia es un país específico de America del Sur: más de $60 \%$ de su población son indios, y a lo largo de toda la historia era uno de los países más pobres y más inestables en la región con mayor número de golpes de Estado.

La nueva Constitución de Bolivia consiste en 5 secciones y 411 artículos. Según ella el Presidente se elige por sufragio universal, directo y secreto con el derecho de ser reelecto para segundo mandato ${ }^{1}$. Si ninguna de las candidaturas no reúne la mayoría de votos, igual que en otros países de la región, realizará una segunda vuelta electoral (antes en esta situación al Presidente lo elegía el Congreso). Por los resultados del referendo es posible una revocatoria anticipada del mandato de los altos funcionarios. 
La Ley Orgánica prevé un carácter electivo de autoridades locales y centrales y reconoce la necesidad de descentralización. Bolivia se constituye en un Estado Plurinacional Unitario fundado en la pluralidad y el pluralismo político, económico, jurídico, cultural y lingüístico, dentro del proceso integrador del país ${ }^{2}$. Al mismo tiempo Bolivia se organiza territorialmente en departamentos, provincias, municipios y territorios indígena originario campesinos $^{3}$. La Nueva Constitución da más autonomía a nueve departamentos que podrán convocar sus propias asambleas constituyentes.

La particularidad de nueva Ley Orgánica consiste en tener ésta un mecanismo de inserción de la población indígena en el proceso político. Se puede decir que es un mecanismo revolucionario para Bolivia donde hace 40 años a los indios no se los permitía entrar en la Plaza Mayor de La Paz y se consideraban 'la gente de segunda calidad'. Pero ahora está prevista la convocación del nuevo Congreso en el cual tendrán una cuota especial los representantes de tribus indios - la población indígena de Bolivia. Está creando un 'Estado plurinacional' renovado, el derecho a la autonomía y al autogobierno y lo recibirán 36 tribus bolivianos que viven en los Andes. Además, la Constitución reconoce como los idiomas oficiales del Estado el castellano y 36 idiomas de las naciones y pueblos indígena originario campesinos, y también propone respetar a nivel estatal la divinidad Pachamama, la deidad de la Tierra y fertilidad. El conocimiento de dos idiomas estatales, al menos, es una condición indispensable para los que pretende ser funcionario público. Se garantiza a la población indígena una representación fija en todas las autoridades, incluso el Tribunal Constitucional, se le da oportunidad de guiarse por el derecho común. Las comunidades indias reciben en su uso colectivo recursos agrarios, forestales y acuáticos en los lugares de su habitación ${ }^{4}$.

La Constitución establece un sistema económico pluralista que incluye propiedad comunal, estatal, privada y cooperativa. Con eso la prioridad se da, según las tradiciones indígenas, a los sectores estatal y colectivo. El papel clave en la economía debe jugar el Estado al cual pertenecen riquezas naturales, incluso las que no pueden ser privatizadas, como hidrocarburos, recursos acuáticos, energética y sectores clave de la industira. Conforme a la Constitución, el gobierno desde este momento no tiene derecho de reprivatizar los yacimientos de gas y petroleo. En el sector privado la Ley Orgánica da preferencia a los inversionistas nacionales. La Constitución reduce el tamaño

\section{Maracanan}


máximo de la propiedad privada agraria: 77\% de los votados pensaron que una persona no puede tener en su propiedad más de 5 mil hectáreas. El artículo 56 de la Constitución "garantice el derecho a la propiedad privada si su uso no hace daño a los intereses colectivos". Según los datos oficiales, 81\% de los ciudadanos piensan que 5 mil hectáreas ya es una propiedad grande.

Cerca de 100 artículos del total de los 400 de la Constitución determinan los derechos sociales de los grupos diferentes de población (indios, mujeres, niños, adultos, familias, descapacitados, detenidos y hasta usuarios y consumidores), están inscritos en detalles los derechos fundamentales económicos, ecológicos y sociales, el derecho a la propiedad, a la salud, la educación y seguridad social, al desarrollo de la cultura y del deporte ${ }^{5}$. La Constitución reconoce el derecho de los bolivianos al agua potable, energía electríca, teléfono. Son los servicios básicos reconocidos como bienes públicos que no están para privatizar. Se presta mucha atención a la conservación de la biodiversidad y protección de los recursos genéticos. El Estado se encarga de proteger las plantaciones de coca que es considerada el patrimonio cultural de los antepasados.

Como la Constitución proclama la independencia del Estado de la religión, la Iglesia católica pierde su estatus oficial ${ }^{6}$.

En el campo de la política exterior está fijado el derecho de Bolivia a la salida al Pacífico, Bolivia se proclama un Estado pacifista y prohíbe la instalación de bases militares extranjeras en su territorio ${ }^{7}$.

El Presidente Evo Morales trata de validar jurídicamente su proyecto radical izquierdista 'Socialismo del siglo XXI' que, según él, da oportunidades y derechos iguales a los diferentes grupos de población.

El Presidente de Bolivia Evo Morales es el primer representante del pueblo indio que ocupó este alto cargo y declaró varias veces que la nueva Ley Orgánica “iba a sentar las bases de nuevo Estado”. Al recorrer el camino a la presidencia del pastor de lamas y líder del sindicado de llamados 'cocaleros' campesinos dedicados al cultivo de hoja de coca- prometió más de una vez que en el fundamento del Estado va a estar justicia social.

La oposición, que prácticamente no había participado en la elaboración del proyecto de la Constitución, resultó estar descontenta del mismo mecanismo de aprobarla (antes para cambiar la Ley Orgánica fue necesario tener la mayoría cualificada y no pluralidad absoluta de legisladores constituyentes). Contra la 
Constitución cargó la pluralidad absoluta de población de 4 departamentos de los 9 más ricos en recursos materiales y económicos. La oposición abogó por la conservación de amplia autonomía de los departamentos, aceptada de una manera unilateral, inculpó al gobierno de imponer el socialismo y totalitarismo y al Presidente de usurpar el poder. Los grandes empresarios y terratenientes están descontentos de la linea gobernamental a la nacionalización y de las restricciones impuestas a la propiedad privada. Los representantes de las capas medias urbanas acusaban al mandatario de cierto 'racismo indio' y menosprecio de los intereses de la población blanca y mestiza. Después de haber vencido Evo Morales en las elecciones de 2005, Santa Cruz se convirtió en el centro de así llamada 'media luna' en la cual entran los departamentos orientales - Pando, Beni, Santa Cruz y Tarija. A estos departamentos los une el deseo común de recibir autonomía de La Paz. En ellos, a diferencia de los departamentos occidentales, la población indígena no es predominante. Entre los departamentos orientales y occidentales, además de las contradicciones políticas y culturales, existen también las económicas. Los departamentos de 'media luna' se caracterizan por el nivel de desarrollo más alto, ellos dan un 48\% del PIB de Bolivia y tienen en su territorio grandes yacimientos de hidrocárburos.

La Iglesia católica también está en oposición a Evo Morales por haber perdido, por primera vez en 500 años de su historia, el estatus de religión estatal de Bolivia, y su parte conservativa vea en nueva legislación un reconocimiento indirecto de legalización de abortos y matrimonios no tradicionales. La legalización de coca provoca protestas por parte de los EE.UU. y UE, y el deseo de Bolivia de conseguir la salida al mar intensifica el descontento de sus vecinos, Perú y Chile.

Una vez aprobada la Constitución, en el país comenzaron las transformaciones económicas y políticas de gran escala. Por su nivel y envergadura se puede considerarlas revolucionarias. El 6 de diciembre de 2009 en Bolivia se celebraron las primeras elecciones generales: fueron electos el presidente, vicepresidente, diputados y senadores de la Asamblea Plurinacional Legislativa que sustituyó el Congreso. Por la presidencia lucharon 8 candidatos. Además, la población de La Paz, Cochabamba, Chuquisaca, Oruro y Potosí expresaron su opinión respecto al estatus autónomo de sus departamentos.

Al recibir el 63\% para el segundo período de cinco años, fue reelecto el presidente en ejercicio, líder del Movimiento al socialismo (MAS) Evo Morales

\section{Maracanan}


Aima. El Movimiento al socialismo pudo cumplir su tarea y contar con dos tercios de la Asamblea Plurinacional Legislativa que consiste en 130 deputados y 36 senadores. Antes la oposición controlaba el Senado lo que era un obstaculo fundamental para que el gobierno realizara sus iniciativas. Ahora durante su segundo mandato, desde el 22 de enero de 2010, Evo Morales tiene bastante poder para hacer enmiendas necesarias en la Constitución y reformar las instituciones democráticas clave -Tribunal Constitucional, Tribunal Supremo de Justicia y Tribunal Supremo Electoral- sin que la oposición parlamentaria pueda impedirle.

Según E. Morales y sus partidarios, dos mandatos son insuficientes para realizar reformas planeadas poreso después de las elecciones en la primera rueda de prensa Evo Morales notó que la nueva Constitución le permite presentar su candidatura en las elecciones de 2015.

El 4 de abril de 2010 en Bolivia se realizaron las elecciones regionales en las cuales fueron electos los prefectos de 9 departamentos, alcaldes de 337 municipios y deputados de asambleas departamentales. Los candidatos del Movimiento al socialismo vencieron en Cochabamba (60\%), La Paz (47\%), Chuquisaca (49\%), Potosí (63\%), Oruro (58\%) donde las posiciones del partido gobernante tradicionalmente son muy fuertes. En el departamento oposicionista Pando en varios colegios electorales realizaron la segunda votación por infracciones que habían tenido lugar durante las elecciones. En otros departamentos que entran en así llamada "media luna de gas" venció la oposición. En Santa Cruz y Tarija fueron reelectos los perfectos en ejercicio R. Costas (54\%) y M. Coscio (50\%). Los candidatos del partido gobernante recibieron respectivamente $37 \%$ y $44 \%$ de votos. Según los resultados, fueron constituidas las asambleas de departamentos que, conforme a la Constitución de 2009, recibirían facultades legislativas que les asignan el estatus de autonomías. Entre 267 miembros de asambleas 23 pertenecen a la población indígena.

Las elecciones regionales realizadas dieron inicio a la elección de autoridades autónomas de los departamentos y continuaron el proceso de construcción del Estado Plurinacional decentralizado conforme a nueva Constitución. Podemos decir que su resultado es el avanzar de Bolivia en crear un sistema social-económico y político más estable.

Los cambios sistémicos comenzaron en la economía también, a partir de 2006 se realizaron 4 nacionalizaciones. El 1 de mayo de 2006 E. Morales 
declaró la nacionalización de la industria petrolera y de gas: 5 empresas extranjeras pasaron a manos de la empresa estatal Yacimientos Petroliferos Fiscales Bolivianos (YPFB). El 9 de febrero de 2007 fue expropriada la empresa metalúrgica sueca Glencore (tratados de compensaciones no están firmados hasta hoy día). El 1 de mayo de 2007 nacionalizaron la empresa Entel cuyas acciones en 50\% pertenecían a la corporación italiana Telecom. El 1 de mayo de 2009 bajo del control de Estado pasaron la sucursal de British Petroleum - Air-BP que especializaba en suministros de combustible de aviación, tres empresas energéticas - productoras de $80 \%$ de la energía eléctrica consumida en el país, y una proveedora local de energía eléctrica en Cochabamba. Antes, 50\% de acciones de las empresas Corani-Guaracachi pertenecieron a las firmas francesas, y la mitad del capital de Valle Hermoso la tuvo una empresa británica. Las acciones de Luz y Fuerza de Cochabamba fueron repartidas entre los accionistas privados bolivianos. Todas las empresas se privatizaron a mediados de los 90. La Empresa Nacional de Electricidad de Bolivia (ENDE), que pertenece al Estado, se hace nuevo propietario. Según cálculos del gobierno, la nacionalización energética permite bajar los precios de energía en 20\%, tanto para la población como para las necesidades de producción, lo que a su vez ayuda a fomentar las PYMes.

En Bolivia se usan dos herramientas principales de la estatización económica: nacionalización y creación de las empresas estatales. En el país se prefiere un variante 'suave' de nacionalización cuando el Estado compra el paquete de control a las empresas privadas. Se quiere aumentar la participación del Estado en la economía hasta el 35\%.

Durante este tiempo Bolivia y Venezuela suscribieron 15 acuerdos incluso la de creación de empresas gran nacionales en los sectores petrolero y de gas. Las empresas conjuntas de este tipo son uno de los mecanismos de integración económica y reforzamiento del sector estatal en el marco de ALBA donde las economías de Venezuela y Bolivia tienen la importancia clave. Los ingresos de sus exportaciones "deben ser repartidos de una manera justa entre los habitantes de todo el país incluso la población de regiones pobres montañosas".

La eficiencia económica del programa de Morales parece impresionante en un ambiente de la crisis financiero-económica en desarrollo. La nacionalización de hidrocarburos llevó a aumentar los ingresos del Estado de 992

\section{Maracanan}


millones de dólares en 2005 a 7,1 mil millones en 2009. En 2009 con aumento máximo de los salarios, en todo el periodo de gobernar Evo Morales, la inflación fue sólo $0,26 \%$.

El Presidente piensa que la nueva Constitución sentó las bases de la sociedad que va por el camino hacia 'Socialismo del siglo XXI', que ayuda a realizar la revolución 'democrática y cultural' en Bolivia. Su resultado más importante es que a la palestra política y social salió la población indígena del país - los indios. 
198

Notas e Referências

1 Nueva Constitucion Politica del Estado. Articulo 167.

2 Nueva Constitucion Politica del Estado. Articulo 1.

3 Nueva Constitucion Politica del Estado. Articulo 270.

4 Nueva Constitucion Politica del Estado. Articulo 192.

5 Nueva Constitucion Politica del Estado. Articulo 13-110.

6 Nueva Constitucion Politica del Estado. Articulo 4.

7 Nueva Constitucion Politica del Estado. Articulo 10. 